Cinémas

Revue d'études cinématographiques

Journal of Film Studies

\title{
Notes au lecteur
}

Volume 11, numéro 2-3, printemps 2001

Eisenstein dans le texte

URI : https://id.erudit.org/iderudit/024844ar

DOI : https://doi.org/10.7202/024844ar

Aller au sommaire du numéro

Éditeur(s)

Cinémas

ISSN

1181-6945 (imprimé)

1705-6500 (numérique)

Découvrir la revue

Citer ce document

(2001). Notes au lecteur. Cinémas, 11(2-3), 9-10. https://doi.org/10.7202/024844ar

Ce document est protégé par la loi sur le droit d'auteur. L'utilisation des services d'Érudit (y compris la reproduction) est assujettie à sa politique d'utilisation que vous pouvez consulter en ligne.

https://apropos.erudit.org/fr/usagers/politique-dutilisation/
Cet article est diffusé et préservé par Érudit.

Érudit est un consortium interuniversitaire sans but lucratif composé de l’Université de Montréal, l'Université Laval et l'Université du Québec à Montréal. Il a pour mission la promotion et la valorisation de la recherche. https://www.erudit.org/fr/ 


\section{Notes au lecteur}

\section{Sur l'établissement des textes inédits d'Eisenstein}

Les divers textes inédits d'Eisenstein - inédits sinon en russe pour quelques-uns d'entre eux - que l'on pourra lire dans ce numéro ont été traduits d'après les manuscrits originaux déposés au RGALI (Archives d'État russes de la littérature et de l'art), c'est-à-dire dans leur état de brouillon ou d'esquisse. Aucun de ces textes n'avait en effet été préparé par leur auteur pour la publication. Ils comportent donc un certain nombre d'obscurités, d'inachèvements, d'abréviations diverses par rapport auxquels les éditeurs sont intervenus le moins possible, dans le texte même, préférant donner des renseignements dans les notes ou commentaires. Parmi les conventions adoptées, il faut cependant relever celles-ci : les mots abrégés selon l'idiolecte eisensteinien sont complétés entre crochets, certains mots de liaison ou de chevilles apparaissent également entre crochets. Les mots apparaissant dans le texte original en graphie latine - qu'ils soient en français, allemand ou anglais - sont donnés ici en caractères romains, suivis d'un astérisque et ils sont traduits entre crochets à l'exception des mots français. Les notes appelées par les chiffres romains sont d'Eisenstein, celles qui sont appelées par les chiffres arabes sont de notre cru.

S'agissant des deux lettres à Léon Moussinac conservées à la Bibliothèque nationale de France (fonds Moussinac), elles ont été écrites en français par Eisenstein et nous avons respecté ici son orthographe et sa grammaire, parfois fantaisistes et le plus souvent savoureuses.

\section{Sur les références bibliographiques}

Dans les notes de fin de document, les références à des textes (ouvrages, articles, etc.) sont, normalement, complètes (nom de l'auteur, suivi du titre, de la ville de l'éditeur, du nom de l'éditeur, etc.). Ce n'est que dans le corps du texte que nous recourons au système abrégé (auteur, année, page), renvoyant ainsi à la liste des "Ouvrages cités", située en toute fin de document, 
après les notes. Pour ce numéro, spécial à bien des égards, nous avons fait une entorse volontaire à notre protocole. Afin d'alléger le volume et la taille des notes, nous y avons utilisé le système abrégé pour toutes les références aux textes mêmes d'Eisenstein. On en trouvera la liste, en fin de dossier, à la page 271 ("Textes d'Eisenstein cités dans l'ensemble du numéro"). Il est à noter, aussi, que, par conséquent, les ouvrages d'Eisenstein cités dans chacun des articles ne se retrouvent pas dans la liste des «Ouvrages cités" propre à chacun des articles.

Étant donné l'extrême disparité des éditions d'une langue à l'autre, et parfois dans la même langue, et le "retard" de l'édition française interrompue depuis 1985 , il n'a pas toujours été possible de donner au lecteur, dans l'ensemble du numéro, une référence française aux textes d'Eisenstein publiés en russe, en anglais ou en italien. Aussi verra-t-on, ici, le même texte source être parfois référé à différentes éditions et langues. Cette étrangeté, qui fait qu'aucune édition ne peut, actuellement, faire autorité, quelle que soit son ampleur (nous pensons en particulier aux Opere scelte italiennes et aux Selected Writings anglaises, qui correspondent chacune à des états différents de la connaissance du corpus), témoigne de la sorte d'une situation dont toute une partie de ce numéro traite. Nous avons renoncé, pour les mêmes raisons, à renvoyer à la seule mention du volume ou du tome des Euvres, Euvres choisies, etc. dont les différentes numérotations et les découpages ajouteraient à la confusion.

\section{Sur la translittération des patronymes russes}

Dans les notes de fin de document et dans les sections "Ouvrages cité ", la graphie des noms propres des auteurs russes differe parfois de la graphie utilisée dans le corps du texte, et il peut $y$ avoir des variations d'une note à l'autre. Ainsi le patronyme d'Eisenstein, à titre d'auteur d'un ouvrage paru dans une autre langue que le français, est-il parfois orthographié "Ejzenstejn». Ainsi, aussi, trouve-t-on à la fois "Chklovski" et "Sklovskij", "Rodtchenko " et "Rodcenko", etc. Nous avons autant que possible respecté la translittération à laquelle les chercheurs devront faire appel s'ils veulent trouver les documents cités dans le texte. 